
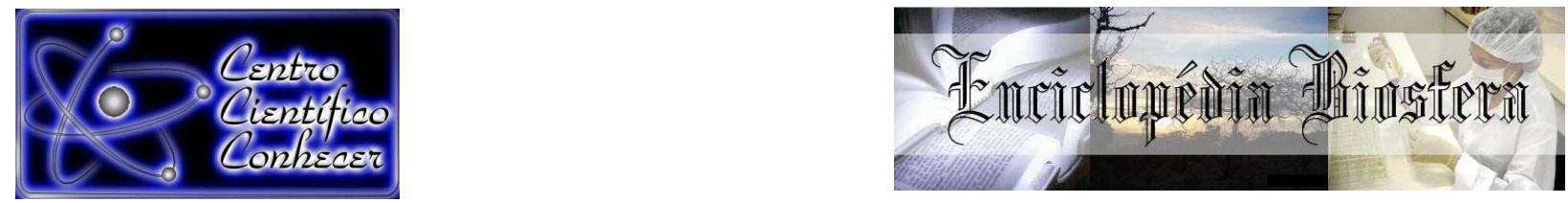

\title{
EFEITO DA IRRIGAÇÃO E DO TIPO DE CULTIVO SOBRE A RIQUEZA E DIVERSIDADE CROMOGÊNICA DE ACTINOBACTÉRIAS DO SOLO DE UMA REGIÃO DO SEMIÁRIDO DO CEARÁ
}

Valéria Maria Araújo Silva'; José Vinícius Leite Lima1; Patrícia de Menezes Gondim¹ Claudia Miranda Martins ${ }^{2}$; Suzana Claudia Silveira Martins ${ }^{2}$

1 Estudantes do Programa de Pós-Graduação em Ecologia e Recursos Naturais da Universidade Federal do Ceará

2 Professora Doutora do Departamento de Biologia da Universidade Federal do Ceará (suzana220@gmail.com) Fortaleza-Brasil

\section{Recebido em: 08/09/2015 - Aprovado em: 14/11/2015 - Publicado em: 01/12/2015 DOI: http://dx.doi.org/10.18677/Enciclopedia_Biosfera_2015_016}

\section{RESUMO}

O semiárido do Nordeste brasileiro, representado pelo bioma Caatinga, caracterizase como um ambiente de pouca disponibilidade hídrica e solos rasos, que refletem diretamente no equilíbrio do ecossistema. A irrigação é considerada uma opção estratégica para reduzir essa escassez e melhorar as características do solo. Por outro lado, a água utilizada na irrigação pode induzir a deposição de sais aumentando a salinidade, já elevada em áreas semiáridas, promovendo a degradação química e biológica do solo. Considerando o papel ecológico das actinobactérias no solo, esse trabalho objetivou quantificar, e avaliar o efeito da irrigação sobre a diversidade cultural de actinobactérias do solo de mata nativa e de um perímetro irrigado de uma região de Caatinga. Para isso, amostras de solo de ambas as áreas foram coletadas de uma região do semiárido no Estado do Ceará e a população de actinobactérias foi quantificada, sendo isoladas e caracterizadas um total de 39 cepas. A densidade populacional ficou em torno de $1,0 \times 10^{5}$ UFC. $\mathrm{g}^{-1} \mathrm{e}$ não variou entre as áreas avaliadas. As cepas foram classificadas em dezessete grupos em relação às características culturais avaliadas. Os índices de diversidade Shanonn e de Simpson e o de riqueza de Margalef foram maiores nas áreas irrigadas e a cobertura vegetal não influenciou a diversidade.

PALAVRAS-CHAVE: Bactérias, caatinga, pigmentos coloniais, solo. 


\title{
EFFECT OF IRRIGATION AND TYPE OF CULTIVATION ON RICHNESS AND DIVERSITY OF CHROMOGENIC ACTINOBACTERIA OF SOIL FROM CEARÁ SEMIARID REGION
}

\begin{abstract}
The semi-arid region of northeastern Brazil, represented by the Caatinga biome, is characterized as an environment of low water availability and shallow soils, which reflect directly on ecosystem balance. Irrigation is considered a strategic option to reduce this shortage and improve soil characteristics. On the other hand, water used for irrigation can induce the deposition of salts increasing salinity, already high in semi-arid areas, promoting chemical degradation and biological soil. Considering the ecological role of actinobactéria in the soil, this study aimed to quantify and evaluate the effect of irrigation on the cultural diversity of actinobacteria in soil of the native and irrigated perimeter of a Caatinga region. For this, soil samples from both areas were collected in a semi-arid region in the state of Ceará and the population of actinobacteria was quantified, being isolated and characterized a total of 39 strains. Population density was around $1.0 \times 10^{5} \mathrm{CFU}^{-1}$ and did not vary among the evaluated areas. The strains were classified into seventeen groups regarding valued cultural characteristics. The Shanonn diversity index and Simpson and the richness of Margalef were higher in irrigated areas and the vegetation cover did not influence the diversity.
\end{abstract}

KEYWORDS: Bacteria, colonial pigments, soil, caatinga

\section{INTRODUÇÃO}

No semiárido a restrição hídrica e a distribuição irregular das chuvas são fatores que influenciam negativamente as características do solo (AMARAL et al., 2013), principalmente as populações microbianas (BARROS et al., 2010). A irrigação é uma estratégia que, promove alterações microclimáticas, que por estimular o crescimento microbiano, influenciando diretamente nos parâmetros de qualidade do solo. Um aspecto importante em um sistema de irrigação é a qualidade da água, que associada às condições climáticas da região, gera um problema muito comum nos perímetros irrigados do nordeste brasileiro, a salinidade (VASCONCELOS, 2014). Os sais dissolvidos na água de irrigação, mesmo em baixas concentrações, podem ser incorporados ao solo, alterando as propriedades físicas e químicas e afetando negativamente a comunidade microbiana do referido habitat (AGUIAR-NETTO et al., 2007).

A região semiárida do Nordeste brasileiro compreende uma área de 969.589 km² (SÁ, 2010), que tem como característica principal a irregularidade dos períodos de chuva. Assim, a implantação de perímetros irrigados nessa região, surgiu como alternativa para os longos períodos de estiagem (VASCONCELOS, 2014).

O Perímetro Irrigado Baixo-Acaraú (PIBAU) está localizado na região norte do Estado do Ceará, no trecho final da bacia do Rio Acaraú, abrangendo áreas dos municípios de Acaraú, Bela Cruz e Marco (JALES et al., 2010). Em geral, os solos são profundos, bem drenados, de textura média ou média/leve e muito permeáveis (BRASIL, 2015).

Entre os micro-organismos componentes da microbiota do solo que desempenham funções essenciais para o equilíbrio ecológico do referido habitat, destacam-se as actinobactérias. Representam um dos grupos mais abundantes e 
diversificados em relação ao número de espécies dentro do domínio Bactéria (VENTURA et al., 2007). São bactérias Gram-positivas com predomínio de citosina e guanina em seu genoma (GOODFELLOW \& WILLIAMS, 1983), inicialmente classificadas como um grupo intermediário entre bactérias e fungos (ARAÚJO, 1998). Apresentam morfologia específica, micélios ramificados e crescimento lento (VENTURA et al., 2007). Produzem pigmentos de cores diversificadas que caracterizam o grupo (AMSAVENI et al., 2015), bem como enzimas extracelulares e importantes metabólitos secundários (HO et al., 2002; VENTURA et al., 2007).

As actinobactérias são adaptáveis a uma grande variedade de habitats, como solos com baixo teor de umidade (LEBLANC, 2008), típico de regiões semiáridas. Nesse ecossistema, participam da decomposição da matéria orgânica, do ciclo de nutrientes e no fluxo de energia (TSAI et al., 1992; SHANMUGAPRIYA et al., 2012;). Também auxiliam na fixação de nitrogênio, aumentam a produção de húmus, produzem hormônios, importantes para o crescimento vegetal, antibióticos, que podem evitar ou suprimir algumas doenças em plantas (SADEGHI et al., 2012; PALANIYANDI et al., 2013), além dos pigmentos, que contribuem para resistência ambiental (WOHL \& MCARTHUR, 1998; BARAKATE et al., 2002; AMSAVENI et al., 2015). É interessante destacar que a detecção das actinobactérias por métodos moleculares é menor do que a partir de métodos dependentes de cultivo, devido à dificuldade de extrair o DNA em função da resistência da parede celular característica desse tipo de bactérias (JANSSEN et al., 2002). Diante do exposto, este trabalho teve por objetivo avaliar o efeito da irrigação sobre a riqueza e diversidade cultural de actinobactérias de uma região do semiárido no Estado do Ceará.

\section{Caracterização da área}

\section{MATERIAL E MÉTODOS}

A área de estudo esta localizada na Fazenda Vale Frutas, lote T4 (37’26" S, 408'48" W), dentro do Perímetro Irrigado Baixo Acaraú (PIBAU) no município de Marco, Estado do Ceará. A vegetação da área é do tipo Caatinga arbustiva, complexo vegetacional da zona litorânea e floresta mista dicotilo-palmácea (ANDRADE-LIMA, 1981). O solo da área é caracterizado como Neossolo quartizarênico. O clima é tropical quente semiárido, com temperatura média variando de $26^{\circ} \mathrm{C}$ a $28^{\circ} \mathrm{C}$. Ocorrência de período chuvoso que compreende o período de fevereiro a abril com pluviosidade anual de 1.096,9mm (IPECE, 2013).

\section{Amostragem}

As amostras de solo foram coletadas em área de Caatinga preservada sem irrigação e em área irrigada através de microaspersão na qual estavam presentes duas culturas. A cultura de feijão-caupi (Vigna unguiculata L. Walp) foi cultivada no espaçamento de plantio de 0,8 m entre linhas e 0,3 m entre plantas e em área adjacente encontrava-se o cultivo de goiaba (Psidium guajava L.) no espaçamento de plantio de $7 \mathrm{~m}$ entre linhas e $5 \mathrm{~m}$ entre plantas.

A coleta do solo foi realizada durante o mês abril no final do período considerado chuvoso. Em cada área de vegetação foram distribuídos aleatoriamente cinco quadrantes de $25 \mathrm{~m}^{2}(5 \mathrm{~m} \times 5 \mathrm{~m})$, respeitando uma distância mínima de $10 \mathrm{~m}$ entre os mesmos. Foram coletadas cinco amostras compostas de solo em cada 
bloco, numa profundidade de $0-10 \mathrm{~cm}$ da camada superior com auxilio de uma enxada de jardinagem. A escolha dos blocos foi realizada por sorteio. As amostras foram acondicionadas em sacos plásticos etiquetados, conservadas em caixas de isopor com gelo e encaminhadas para o Laboratório de Microbiologia Ambiental (LAMAB) do Departamento de Biologia da Universidade Federal do Ceará (UFC).

\section{Preparação das amostras}

De cada amostra homogeneizada foram pesados $10 \mathrm{~g}$ de solo que foram diluídos em $90 \mathrm{~mL}$ de solução salina $0,85 \%$. Os frascos foram mantidos sob agitação em mesa agitadora orbital com velocidade de 145 rpm por 30 minutos (correspondentes às diluições $10^{-1}$ ). A partir destas diluições foram preparadas diluições seriadas até a $10^{-4}$ (LIMA et al., 2014).

\section{Contagem de actinobactérias}

A população de actinobactérias foi determinada pelo uso da técnica da semeadura em superfície no meio de cultivo Caseína Dextrose Ágar (CDA) com a seguinte composição por litro: $\mathrm{K}_{2} \mathrm{HPO}_{4} 0,5 \mathrm{~g}, \mathrm{MgSO}_{4} .7 \mathrm{H}_{2} \mathrm{O} 0,2 \mathrm{~g}$, glicose $10 \mathrm{~g}$, caseína 0,2 g, nistatina 0,05 mg e pH 6,5-6,6 (KUSTER \& WILLIAMS, 1964; ARIFUZZAMAN et al., 2010). O meio foi distribuído em placas de Petri estéreis e 100 $\mu \mathrm{L}$ das diluições $10^{-2}$ até $10^{-4}$ foram espalhados sobre a superfície das placas, com auxílio de alça de Drigalski, que foram incubadas a $28 \pm 2{ }^{\circ} \mathrm{C}$ por sete dias (SHAIKH et al., 2013). Após esse período foram selecionadas e quantificadas as diluições que apresentaram entre 30 a 300 colônias com características típicas de actinobactérias e o resultado expresso em UFC. $\mathrm{g}^{-1}$ de solo. O ensaio foi realizado em triplicata. A abundância entre as três áreas foi submetida ao teste de Kruskal-Wallis a 95\% de significância utilizando o programa GraphPad Prism 5.00 (GraphPad Software *, San Diego, CA)

\section{Caracterização Cultural}

A partir do crescimento no meio CDA foi feita uma avaliação das características das colônias sendo selecionadas para a pesquisa as culturas com características distintas, totalizando 39 cepas.

\section{Coloração de Gram}

Foi realizada a coloração de Gram, conforme KERN \& BLEWINS (2003), para verificar a pureza das culturas. Por meio de esfregaço foi depositada uma gota do isolado de cada actinobactéria, ressuspensa sobre a lâmina e feito um esfregaço com auxílio de alça. Após os esfregaços ficarem ao ar em uma superfície plana foram passados três vezes pela chama.

Após esfriar o esfregaço foi coberto por um minuto com solução fenicada de cristal violeta. Escorreu-se o corante e cobriu-se o esfregaço, durante 1 minuto, com solução de lugol. Lavou-se em água corrente e descorou-se com álcool 95 GL. Por fim, adicionou-se ao esfregaço a solução de fucsina básica por 30 segundos. As lâminas de Gram foram visualizadas em microscópio óptico em aumento de 1000x. 


\section{Cor da massa aérea e pigmento reverso}

Cada cepa foi inoculada por estrias em placas de Petri, após purificação, contendo o meio seletivo para actinobactérias CDA. Em seguida as placas foram incubadas em estufa B.O.D a $28 \pm 2{ }^{\circ} \mathrm{C}$ por 7 dias. $\mathrm{P}$ ara descrição das características culturais foram avaliadas as cores do micélio aéreo e reverso das colônias conforme descrito por WINK (2012), baseada na carta de cores (RAL color charts).

\section{Diversidade}

As cepas de actinobactérias de cada área avaliada foram agrupadas de acordo com as características cromogênicas, ou seja, cores do micélio aéreo e reverso e esses dados foram utilizados para determinar os índices de diversidade (Shannon), de (Simpson) e de riqueza (Margalef) utilizando-se o programa estatístico PAST version 1.69 (Paleontological Statistics) (HAMMER et al., 2001).

\section{RESULTADOS E DISCUSSÃO}

A população de actinobactérias não variou significativamente $(p>0,05)$ entre as áreas nativa (sem irrigação) e cultivada (sob irrigação), sendo registrados valores de $6,3 \times 10^{4}$ UFC. ${ }^{-1}$ na área com cultivo de goiaba (Psidium guajava), 7,9 $\times 10^{4}$ UFC. $g^{-1}$ nas amostras de solo de cultivo do feijão-caupi (Vigna unguiculata) e $10 \mathrm{x}$ $10^{4}$ UFC. $g^{-1}$ na área de Caatinga (Figura 1).

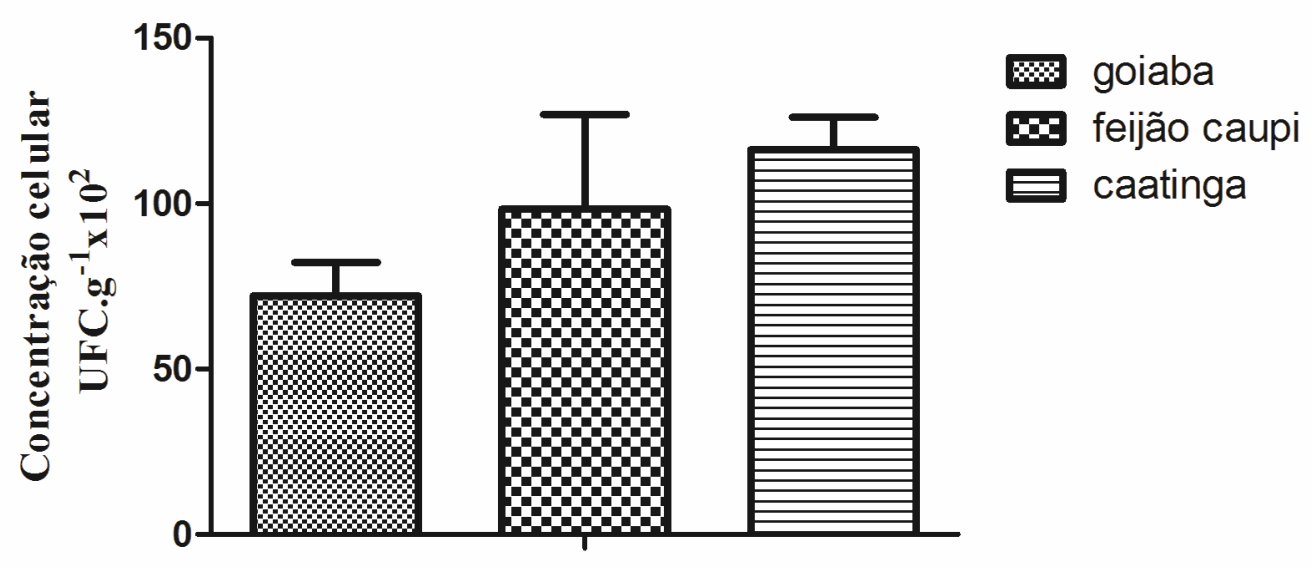

Origem das amostras de solo

FIGURA 1: Concentração de actinobactérias em Unidades Formadoras de Colônias por grama de solo (UFC. $g^{-1}$ ) em amostras de solo de áreas nativas e cultivadas do da região do Baixo Acaraú-CE. 
LOPES et al. (2011) realizaram o monitoramento da salinidade de amostras de solo da área irrigada e da mata nativa na mesma região do presente trabalho. Esses autores verificaram que, de um modo geral, houve aumento na concentração dos sais totais, na área irrigada em relação à mata nativa, no período de 30 meses. D'ALMEIDA et al. (2005) associaram o aumento nas concentrações de sais, entre outros fatores, à má qualidade da água de irrigação. Embora o aumento da salinidade possa interferir negativamente na abundância das populações microbianas do solo, no presente estudo, a concentração de actinobactérias da área irrigada não pareceu ter sido afetada quando comparada aos valores registrados para esse mesmo grupo na mata nativa.

Estudos referentes à densidade populacional de actinobactérias realizados por LIMA et al. (2014) em amostras do solo de mata nativa da Unidade de Conservação da Estação Ecológica de Aiuaba (ESECA), localizada em região semiárida do Ceará mostraram um valor médio de 2,0 × $10^{5}$ UFC. ${ }^{-1}$. MARTINS et al. (2014a) em trabalho com amostras de solo rizosférico do Parque Nacional de Ubajara (PNU), uma unidade de conservação também localizada no Ceará, reportaram uma contagem média de actinobactérias de $6,3 \times 10^{4} \mathrm{UFC} . \mathrm{g}^{-1}$. Outra pesquisa sobre a abundância de actinobactérias de uma área de mata nativa no município de Quixadá no Ceará mostrou que a população foi de 2,3 x $10^{4}$ UFC. $g^{-1}$ (MARTINS et al., 2014b). Embora a densidade microbiana no solo varie com a localização geográfica, temperatura, tipo de solo, $\mathrm{pH}$, concentração de matéria orgânica e umidade (GORLACH-LIRA \& COUTINHO, 2007; ARIFUZZAMAN et al., 2010), a abundância da população de actinobactérias nas amostras de solo do Baixo Acaraú tanto da mata nativa como das áreas irrigadas foi semelhante aos valores reportados por outros autores para diferentes áreas do semiárido.

Segundo AMAL et al. (2011), AUGUSTINE et al. (2013) e MABROUK \& SALEH (2014) a cor do micélio aéreo e reverso, resultante da produção de pigmentos, é um critério taxonômico determinante para a identificação de actinobactérias. Tendo em conta a importância desse critério, a carta de cores de RAL (RAL color charts) foi adaptada com o objetivo de padronizar a classificação de cepas de actinobactérias isoladas de diferentes regiões do semiárido de modo a permitir a comparação entre os resultados. Portanto, a partir da análise da cor do micélio aéreo e do micélio reverso (Tabela 1) foram selecionadas e caracterizadas 39 cepas de actinobactérias denominadas BA (Baixo Acaraú) seguidas de sua respectiva numeração. 
TABELA 1: Caracterização cultural das cepas de actinobactérias isoladas de amostras de solo do Perímetro Irrigado do Baixo Acaraú, no Estado do Ceará de acordo carta de cores (RAL color charts).

\begin{tabular}{|c|c|c|}
\hline CEPAS & $\begin{array}{c}\text { COR DO MICÉLIO } \\
\text { AÉREO }\end{array}$ & $\begin{array}{l}\text { COR DO MICÉLIO } \\
\text { REVERSO }\end{array}$ \\
\hline BA-01 & Cinza (RAL9007) & Creme (RAL 9001) \\
\hline BA-02 & Cinza (RAL 9002) & Branco (RAL 9010) \\
\hline BA-03 & Branco (RAL 9010) & Branco (RAL 9010) \\
\hline BA-04 & Cinza (RAL 9002) & Branco (RAL 9010) \\
\hline BA-05 & Cinza (RAL9007) & Cinza (RAL 9002) \\
\hline BA-06 & Cinza (RAL 9006) & Cinza (RAL 9002) \\
\hline BA-07 & Cinza (RAL 7039) & Cinza (RAL 9002) \\
\hline BA-08 & Branco (RAL 9010) & Cinza (RAL 9002) \\
\hline BA-09 & Rosa (3015) & Rosa (3015) \\
\hline $\mathrm{BA}-10$ & Cinza (RAL9007) & Cinza (RAL 9006) \\
\hline $\mathrm{BA}-11$ & Cinza (RAL 7039) & Cinza (RAL 7040) \\
\hline BA-12 & Branco (RAL 1013) & Amarelo (RAL 1003) \\
\hline $\mathrm{BA}-13$ & Cinza (RAL 7046) & Marrom (RAL 7005) \\
\hline BA-14 & Cinza (RAL 7004) & Cinza (RAL 7008) \\
\hline BA-15 & Marrom (RAL 8025) & Cinza (RAL 9006) \\
\hline $\mathrm{BA}-16$ & Creme (RAL 9001) & Creme (RAL 9001) \\
\hline $\mathrm{BA}-17$ & Branco (RAL 9010) & Creme (RAL 9001) \\
\hline BA-18 & Cinza (RAL 9018) & Cinza (RAL 9002) \\
\hline BA-19 & Amarelo (RAL 1016) & Amarelo (RAL 1016) \\
\hline BA-20 & Cinza (RAL9007) & Verde (RAL 7006) \\
\hline BA-21 & Branco (RAL 9010) & Verde (RAL 7006) \\
\hline BA-22 & Cinza (RAL 7004) & Rosa (RAL 3015) \\
\hline BA-23 & Cinza (RAL 9002) & Marrom (RAL 7005) \\
\hline BA-24 & Branco (RAL 9010) & Branco (RAL 9010) \\
\hline BA-25 & Creme (RAL 9001) & Creme (RAL 9001) \\
\hline BA-26 & Branco (RAL 9010) & Branco (RAL 9010) \\
\hline BA-27 & Creme (RAL 9001) & Creme (RAL 9001) \\
\hline BA-28 & Creme (RAL 9001) & Creme (RAL 9001) \\
\hline BA-29 & Cinza (RAL9007) & Creme (RAL 9001) \\
\hline BA-30 & Cinza (RAL 9018) & Cinza (RAL 9018) \\
\hline BA-31 & Cinza (RAL 9006) & Cinza (RAL 9006) \\
\hline BA-32 & Cinza (RAL 9018) & Cinza (RAL 9018) \\
\hline BA-33 & Branco (RAL 9010) & Cinza (RAL 7047) \\
\hline BA-34 & Cinza (RAL9007) & Creme (RAL 9001) \\
\hline BA-35 & Cinza (RAL9007) & Cinza (RAL 7032) \\
\hline BA-36 & Verde (RAL 7009) & Cinza (RAL 7035) \\
\hline BA-37 & Azul (RAL 5024) & Marrom (RAL 7005) \\
\hline BA-38 & Cinza (RAL9007) & Cinza (RAL 9018) \\
\hline BA-39 & Amarelo (RAL 1007) & Amarelo (RAL 1006) \\
\hline
\end{tabular}

Todas as cepas foram positivas para à coloração de Gram, confirmando a característica desse grupo bacteriano (GOODFELLOW \& WILLIAMS, 1983). Com relação às cores do micélio aéreo, $49 \%$ apresentaram micélio de coloração cinza seguido das cores branco $(20 \%)$, creme $(13 \%)$, marrom $(8 \%)$, azul $(3 \%)$, verde $(3 \%)$, amarelo (2\%) e rosa (2\%) (Figuras 2 e 3 ). 


\section{Cor do Micélio Aéreo}



$$
\begin{aligned}
& \text { Cinza } \\
& \text { Creme } \\
& \text { Branco } \\
& \text { Marrom } \\
& \text { Rosa } \\
& \text { Amarelo } \\
& \text { Verde } \\
& \text { Azul }
\end{aligned}
$$

FIGURA 2: Cor do micélio aéreo de cepas de actinobactérias da região do Baixo Acaraú-CE.

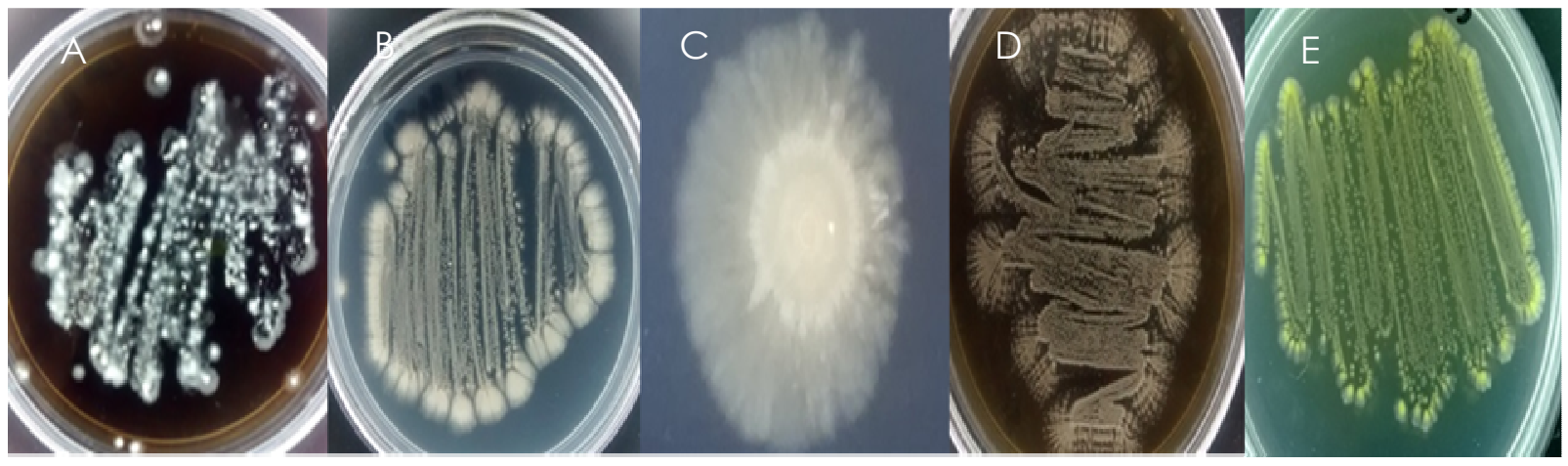

FIGURA 3: Características culturais em cepas de actinobactérias isoladas da região do Baixo Acaraú - CE. (A) BA-21; (B) BA-29; (C) BA- 02; (D) BA-14; (E)

Em relação à cor do micélio reverso houve predomínio das cores cinza, creme e marrom com $30 \%, 30 \%$ e $20 \%$, respectivamente (Figura 4 ). 


\title{
Cor do Micélio Reverso
}

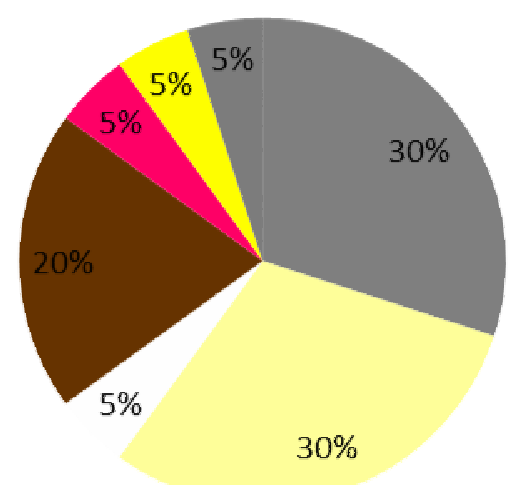

- Cinza
Creme
Branco
- Marrom
nosa
Amarelo
- Verde

FIGURA 4: Cor do micélio reverso de cepas de actinobactérias da região do Baixo AcaraúCE.

\begin{abstract}
AMAL et al. (2011) e AMSAVENI et al. (2015) e destacaram o potencial das actinobactérias em produzir diferentes pigmentos, que podem estar dissolvidos no meio ou retidos nos micélios. No presente trabalho a cor cinza, seguida da creme e branco foram predominantes tanto no micélio aéreo como no reverso da referida estrutura, nas três áreas avaliadas. SILVA (2013) também encontrou a prevalência da cor cinza em $50 \%$ de 36 cepas de actinobactérias do solo rizosférico do bioma Caatinga, seguida do marrom e branco. RAMOS et al. (2015) descrevendo essa característica para 28 cepas de actinobactérias de uma região semiárida do Ceará reportaram o branco, seguido do marrom e cinza, como as colorações que mais se destacaram. Esses resultados mostram que, assim como no presente trabalho, as cores cinza e branca também se destacaram em termos de maior ocorrência, no entanto o percentual de distribuição das cores entre as cepas diferiu nas áreas avaliadas. Essa constatação sugere que actinobactérias oriundas de regiões do semiárido do Ceará são culturalmente diferentes. Tal fato pode ser explicado por AMAL et al. (2011), que destacaram que a produção de pigmentos, sofre influência do $\mathrm{pH}$, temperatura e fonte de carbono disponível. De fato, AMSAVENI et al. (2015), ao isolarem cepas de actinobactérias de diversas regiões da Índia, descreveram principalmente pigmentos das cores amarelo e marrom. Já AUGUSTINE et al. (2013) reportaram a predominância de micélio aéreo branco, cinza e amarelo em cepas de actinobactérias isoladas de sedimentos marinhos.

A partir da análise das características miceliais apresentadas na Tabela 1 às cepas de actinobactérias das três áreas avaliadas foram classificadas em 17 grupos (Tabela 2).
\end{abstract}


TABELA 2: Classificação das cepas de actinobactérias em relação às características culturais e respectivas origens.

\begin{tabular}{|c|c|c|c|c|}
\hline $\begin{array}{l}\text { Grupos } \\
\text { culturais }\end{array}$ & Cepas & $\begin{array}{c}\text { Micélio } \\
\text { aéreo }\end{array}$ & $\begin{array}{l}\text { Lado } \\
\text { reverso }\end{array}$ & Origem \\
\hline \multirow[t]{2}{*}{1} & BA01 & cinza & creme & caatinga \\
\hline & BA29; BA34 & & & goiaba \\
\hline \multirow[t]{2}{*}{2} & BA02 & cinza & branco & $\begin{array}{c}\text { caatinga } \\
\text { feiião }\end{array}$ \\
\hline & BA04 & & & \\
\hline \multirow[t]{2}{*}{3} & BA03; BA24 & branco & branco & feijão \\
\hline & BA26 & & & caatinga \\
\hline \multirow[t]{3}{*}{4} & BA05, BA06, BA10, BA31 & cinza & cinza & feijão \\
\hline & BA07, BA11, BA14, BA30, BA35 & & & caatinga \\
\hline & BA38, BA18, BA32 & & & goiaba \\
\hline \multirow[t]{2}{*}{5} & BA08; & branco & cinza & feijão \\
\hline & BA33 & & & goiaba \\
\hline 6 & BA 09 & rosa & rosa & feijão \\
\hline 7 & BA 12 & branco & amarelo & goiaba \\
\hline \multirow[t]{2}{*}{8} & BA13; & cinza & marrom & caatinga \\
\hline & BA23 & & & goiaba \\
\hline 9 & BA15 & marrom & cinza & feijão \\
\hline \multirow[t]{2}{*}{10} & BA16; BA27, BA28 & creme & creme & feijão \\
\hline & BA25; & & & goiaba \\
\hline 11 & BA17 & branco & creme & goiaba \\
\hline 12 & BA19; BA39 & amarelo & amarelo & goiaba \\
\hline 13 & BA20 & cinza & verde & caatinga \\
\hline 14 & BA21 & branco & verde & caatinga \\
\hline 15 & BA22 & cinza & rosa & feijão \\
\hline 16 & BA36 & verde & cinza & feijão \\
\hline 17 & BA37 & azul & marrom & feijão \\
\hline
\end{tabular}


Embora as actinobactérias façam parte de um grupo de extrema importância nos solos em geral, e, em particular no solo de regiões semiáridas, ainda são incipientes estudos sobre estas bactérias na Caatinga. Assim, embora os dados registrados sejam sugestivos de elevada diversidade cultural é difícil compará-los com resultados de estudos semelhantes.

A diversidade microbiana está intrinsecamente associada aos diversos processos ecológicos do solo, por isso é considerada um importante indicador da qualidade do solo. Essa diversidade pode ser medida por intermédio de índices matemáticos, que levam em consideração informações taxonômicas na definição das unidades de medida (taxa) (ZILLI et al., 2003). Alguns índices, como o de diversidade, de Shannon, Simpson e de riqueza, de Margalef fornecem informações importantes sobre do padrão de distribuição de espécies microbianas dentro do ecossistema (KENNEDY, 1999). A partir dos resultados do dendrograma foram determinados os índices de diversidade (Shannon e Simpson) e riqueza (Margalef) para cada área estudada (Tabela 3).

TABELA 3: Índices de diversidade de Shannon e de Simpson, de riqueza de Margalef e equitabilidade de cepas de actinobactérias de uma região do semiárido do Estado do Ceará.

\begin{tabular}{cccccc}
\hline Áreas & $\begin{array}{c}\text { Total de } \\
\text { morfotipos }\end{array}$ & \multicolumn{5}{c}{ Índices } \\
\cline { 3 - 6 } & & Shannon & Simpson & Margalef & Equitabilidade \\
Caatinga & 12 & 1,589 & 0,7083 & 2,415 & 0,8166 \\
Feijão & 16 & 2,133 & 0,8594 & 3,246 & 0,9265 \\
Goiaba & 11 & 2,020 & 0,8595 & 2,919 & 0,9713 \\
\hline
\end{tabular}

Comunidades microbianas com maior diversidade são consideradas mais produtivas do que aquelas com menor diversidade, pois são capazes de captar os recursos de forma mais eficiente (BECKER et al., 2012). Entre as medidas de diversidade o índice de Shannon é o mais utilizado e dá maior peso para as espécies raras, enquanto o de Simpson se destaca pelo maior peso as espécies dominantes. O índice de Margalef se reporta a riqueza de espécies (MAGURRAN, 1988). No presente estudo, a área correspondente ao cultivo do feijão e da goiaba apresentou índices de diversidade e riqueza superior à área correspondente a mata nativa, tanto em relação aos morfotipos mais raros como os dominantes. Não foi constatada diferença de diversidade e riqueza entre as áreas cultivadas (feijão e goiaba) sugerindo que a cobertura vegetal não tem influência sobre esses parâmetros.

Os menores índices de diversidade e riqueza da mata nativa sugerem que, embora a irrigação possa provocar a degradação do solo, por acúmulo de sais na superfície, à disponibilidade de água parece ser o fator mais decisivo na riqueza e diversidade cultural das actinobactérias do bioma Caatinga. Com relação ao índice de Equitabilidade, também se observou que referido valor foi menor na mata nativa que nas áreas irrigadas. Esse resultado sugere que a distribuição dos morfotipos das actinobactérias foi mais uniforme nas áreas irrigadas que na mata nativa. SANTOS (2001) relata que quanto maior a equitabilidade de espécies de uma comunidade, maior é a resistência aos impactos ambientais.

Embora os índices de diversidade tenham demonstrado diferenças relacionadas às regiões de coleta das amostras, cumpre destacar que alguns morfotipos, como as cepas do grupo $14 \mathrm{com}$ a cor cinza tanto no micélio aéreo como ENCICLOPÉDIA BIOSFERA, Centro Científico Conhecer - Goiânia, v.11 n.22; p.2975 2015 
no lado reverso foram registradas nas três áreas analisadas, independentemente das características do solo.

\section{CONCLUSÕES}

A região do Baixo Acaraú no semiárido do Ceará cultivada sob irrigação apresentou maior riqueza e diversidade de morfotipos coloniais de actinobactérias em comparação com a região de mata nativa. A cobertura vegetal não influenciou os citados parâmetros.

\section{REFERÊNCIAS}

AMAL, A. M.; ABEER, K. A.; SAMIA, H. M.; ABD EL-NASSER H. N.; AHMED, K. A.; EL-HENNAWI, H. M. Selection of pigment (Melanin) production in Streptomyces and their application in printing and dyeing of wool fabrics. Research Journal of Chemical Sciences. v. 1, n. 5, p. 22-28, 2011.

AMARAL, A. J.; HERNANI, L. C.; OLIVEIRA NETO, M. B.; CUNHA, T. J. F.; MELO, A. S. Avaliação de parâmetros relacionados à salinidade do solo em área de fruticultura irrigada no Bioma Caatinga. I Reunião Nordestina de Ciência do Solo, p. 1-4, 2013.

AMSAVENI, R.; SURESHKUMAR, M.; VIVEKANANDHAN, G.; BHUVANESHWARI, $\mathrm{V}$.; KALAISELVI, M. Screening and isolation of pigment producing Actinomycetes from soil samples. International Journal of Biosciences and Nanosciences, v. 2, p. 24-28, 2015.

ANDRADE-LIMA, D. The caatinga dominium. Revista Brasileira de Botânica, v. 4, p. $149-153,1981$.

ARAÚJO, J. M. Estratégias para isolamento seletivo de actinomicetos. In: MELO, I. S.; AZEVEDO, J. L. Ecologia microbiana. Jaguariúna: Embrapa, p. 351-36, 1998.

ARIFUZZAMAN, M; KHATUN, M. R.; RAHMAN, H. Isolation and screening of actinomycetes from Sundarbans soil for antibacterial activity. African Journal of Biotechnology, v. 9, p. 4615-4619, 2010.

AGUIAR-NETTO, A. O.; GOMES, C. C. S.; LINS, C. C. V.; BARROS, A. C.; CAMPECHE, L. F. S. M.; BLANCO, F. F. Características químicas e salinosodicidade dos solos do Perímetro Irrigado Califórnia-SE, Brasil. Ciência Rural, v. 37, n. 6, p. 1640-1645, 2007.

AUGUSTINE, D.; JACOB, J. C.; RAMYA, K.D; PHILIP, R. Actinobacteria from sediment samples of Arabian Sea and Bay of Bengal: Biochemical and physiological characterization. International Journal of Research in Marine Sciences, v. 2, p. 56-63, 2013.

BARAKATE, M.; OUHDOUCH, Y.; OUFDOU, K.; BEAULIEU, C. Characterization of rhizospheric soil streptomycetes from Moroccan habitats and their antimicrobial activities. World Journal Microbiology Biotechnology, v. 17, p. 49-54, 2002. 
BARROS, Y. J.; MELO, V. F.; DIONÍSIO, J. A.; OLIVEIRA, E. B.; CARON, L.; KUMMER, L.; AZEVEDO, J. C. R.; SOUZA, L. C. P. Indicadores de qualidade de solos em área de mineração e metalurgia de chumbo. Revista Brasileira de Ciência do Solo, v. 34, p.1397-1411, 2010.

BECKER, J., EISENHAUER, N., SCHEU, S., JOUSSET A. Increasing antagonistic interactions cause bacterial communities to collapse at high diversity. Ecology Letters, v. 15, p. 468-474, 2012.

BRASIL. Departamento Nacional de Obras Contra as Secas. Perímetro Irrigado Baixo Acaraú. $\quad$ Fortaleza. 2008 Disponível em: http://www.dnocs.gov.br/ dnocs/doc/canais/perimetros_irrigados/ce/baixo_acarau.ht $\mathrm{ml}$ Acesso em: 28 de agosto de 2015.

D'ALMEIDA, D. M. B. A.; ANDRADE, E. M.; MEIRELES, A. C. M. Importância relativa dos íons na salinidade de um Cambissolo na Chapada do Apodi, Ceará. Engenharia Agrícola, v. 25, p. 615-21, 2005.

GOODFELLOW, M.; WILLIAMS, E. Ecology of Actinomycetes. Annual Review of Microbiology, v. 37, p. 189-216, 1983.

GORLACH-LIRA, K.; COUTINHO, H. D. M. Population dynamics and extracellular enzymes activity of mesophilic and thermophilic bacteria isolated from semi-arid soil of Northeastern Brazil. Brazilian Journal of Microbiology, v. 38, p. 135-141, 2007.

HAMMER, O.; HARPER, D. A. T.; RYAN, P. D. Paleontological statistics software package for education and data analysis. Paleontologia Eletronica. 2001.

HO, C.; LO, C.; LAI, N.; CHEAH, H.; WONG, N. Actinomycetes isolated from soil samples from the cocker range Sabah. ASEAN Rev. Biodiversity Environmental Conservation, v. 9, p. 1-7, 2002.

IPECE - Instituto de pesquisa e estratégica econômica do Ceará. Perfil básico municipal-Marco 2013.

JALES, J. V.; PROTELA, S. V. S.; MERA, R. D. M.; ALENCAR-JúNIOR, J. S.; MAYORGA, I. O. Análise da sustentabilidade do Perímetro Irrigado Baixo Acaraú, no Estado do Ceará. Anais....48ํㅜㄹ Congresso da Sociedade Brasileira de Economia, Administração e Sociologia Rural, p. 1-19, 2010.

JANSSEN, P. H.;YATES, P. S.; GRINTON, B. E.; TAYLOR, P. M.; SAIT, M. Improved culturability of soil bacteria and isolation in pure culture of novel members of the divisions Acidobacteria, Actinobacteria, Proteobacteria, and Verrucomicrobia. Applied Environmental Microbiology, v. 68, p. 2391-2396, 2002.

KENNEDY, A. C. Bacterial diversity in agroecosystems. Agriculture, Ecosystems and Environment, v. 74, n. 1, p. 65-76, 1999. 
KERN, M. E.; BLEVINS, K. S. Micologia Médica: Texto e Atlas. 2 ed. São Paulo: Premier, 1999.

KUSTER, E.; WILLIAMS, S. T. Selective media for the isolation of Streptomycetes. Nature, v. 202, p. 928-929, 1964.

LEBLANC, J. C.; GONÇALVES, E. R.; MOHN, W. W. Global response to desiccation stress in the soil actinomycete Rhodococcus jostii RHA1. Applied Environmental Microbiology, v. 74, p. 2627-2636, 2008.

LIMA, J. V. L.; PINHEIRO, M. S.; FIÚZA, L. M. C. G.; MARTINS, S. C. S.; MARTINS, C. M. Populações microbianas cultiváveis do solo e serapilheira de uma unidade de conservação no semiárido brasileiro. Enciclopédia Biosfera, v. 10, p. 2300-2316, 2014.

LOPES, F. B.; CHAVES, L. C .G.; ANDRADE, E. M.; CRISOSTOMO, L. A. Risco de degradação em solo irrigado do perímetro irrigado, Baixo Acaraú, Ceará. Irriga, v. 16, n. 4, p. 424-435, 2011.

MABROUK, M. I.; SALEH, N. M. Molecular Identification and Characterization of Antimicrobial Active actinomycetes strains from Some Egyptian Soils. AmericanEurasian Journal Agriculture \& Environment Scince, v. 14, p. 954-963, 2014.

MAGURRAN, A. E. Ecological diversity and its measurement. New Jersey: Princeton University Press, 179 p. 1988.

MARTINS, C. M.; PINHEIRO, M. S.; FIÚZA, L. M. C. G.; OLIVEIRA, A. V.; MARTINS, S. C. S. Comunidade microbiana cultivável do solo rizosférico de leguminosas no semiárido brasileiro. Enciclopédia Biosfera, v. 10, p. 2858-2868, 2014a.

MARTINS, S. C. S.; PINHEIRO, M. S.; OLIVEIRA, A. V.; FIALHO, J. S.; MARTINS, C. M. Efeito do pousio na recuperação de um solo sob caatinga no semiárido brasileiro. Enciclopédia Biosfera, v. 10, p. 2194-2204, 2014b.

MIYAUCHI, M. Y. H. Biocontrole de fungos patogênicos por actinobactérias isoladas de rizosfera de Araucaria angustifolia. 106 f. Tese (Doutorado em Microbiologia Agrícola) - Universidade de São Paulo, Piracicaba, 2012.

PALANIYANDI, S. A.; YANG, S. H.; ZHANG, L.; SUH, J. W. Effects of actinobacteria on plant disease suppression and growth promotion. Applied Microbiology Biotechnology, v. 97, p. 9621-9636, 2013.

RAMOS, K. A.; BRITO, F. A. E.; NUNES, K. J. F.; MARTINS, C. M.; MARTINS, S. C. S. Caracterização e diversidade cromogênica de actinobactérias de um nicho microbiano preservado do bioma caatinga. Enciclopédia Biosfera, v. 11, p. 21152125, 2015.

SADEGHI, A.; KARIMI, E.; DAHAZI, P. A.; JAVID, M. G.; DALVAND, Y.; ASKARI, H. Plant growth promoting activity of an auxin and siderophore producing isolate 
of Streptomyces under saline soil condition. World Journal of Microbiology and Biotechnology, v. 28, n. 4, p. 1503-1509, 2012.

SÁ, I. B.; CUNHA, J. F.; TEIXEIRA, A. H. C.; ANGELOTTI, F.; DRUMOND, M. A. Desertificação no semiárido brasileiro. ICID+18 2a Conferência Internacional: Clima, Sustentabilidade e Desenvolvimento em Regiões Semiáridas, Fortaleza, 2010.

SANTOS, C. E. R. S. Diversidade de rizóbio nativo da região Nordeste do Brasil capaz de nodular amendoim (Arachis hypogaea), Stylosanthes e Aeschynomene. 178 f. Tese (Doutorado em Ciência do Solo) - Universidade Federal Rural do Rio de Janeiro, Seropédica, 2001.

SHANMUGAPRIYA, S.; SARAVANA, P.S.; KRISHNAPRIYA, M. M.; MYTHILI, A.; JOSEPH, S. Isolation, screening and partial purification of cellulase from cellulase producing bacteria. International Journal of Advanced Biotechnology and Research, v. 3, p. 509-514, 2012.

SHAIKH, N. M.; PATEL, A. A.; MEHTA, S. A.; PATEL, N. D. Isolation and screening of cellulolytic bacteria inhabiting different environment and optimization of cellulase production. Universal Journal of Environmental Research and Technology, v. 3, n.1, p. 39-49, 2013.

SILVA, G. L. Bioprospecção de actinobactérias isoladas da rizosfera de Caesalpinia pyramidalis Tul. do bioma Caatinga. 2013. 93 f. Dissertação (Mestrado em Biotecnologia Industrial) - Universidade Federal de Pernambuco, Recife, 2013.

TSAI, S. M; BARAIBAR, A. V. L; ROMANI, V. L. M. Efeito de fatores do solo. In: CARDOSO, E.J.B.N.; TSAI, S.M.; NEVES, M.C.P. (Eds.). Sociedade Brasileira de Ciência do Solo, p. 59-72, 1992.

VASCONCELOS, M. C. C. A. Salinização do solo em áreas irrigadas: aspectos físicos e químicos. Agropecuária Científica no Semiárido, v.10, n.1, p.20-25, 2014.

VENTURA, M.; CANCHAYA, C.; TAUCH, A.; CHANDRA, G.; FITZGERALD, G. F.; CHATER, K.F.; VAN SINDEREN, D. Genomics of Actinobacteria: tracing the evolutionary history of an ancient phylum. Microbiology Molecular Biology Reviews, v. 71, p. 495-548, 2007.

WINK, J. M. Compendium of actinobacteria. University of Braunschweig. p. 1-37, 2012.

WOHL, D. L.; MCARTHUR, J. V. Actinomycete-flora associated with submerged freshwater macrophytes. FEMS Microbiology Ecology, v. 26, p. 135-140, 1998.

ZILLI, J. E.; RUMJANEK, N. V.; XAVIER, G. R.; COUTINHO, H. L. C.; NEVES, M. C. $P$. Diversidade microbiana como indicador de qualidade do solo. Cadernos de Ciência \& Tecnologia, v. 20, n. 3, p. 391-411, 2003. 